\title{
Conjectures between Two Cournot Firms with Symmetric Information and Their Risk-taking Behaviours*
}

\author{
Suyeol Ryu ${ }^{\mathrm{a}}$ \\ Andong National University \\ Iltae Kim ${ }^{b}$ \\ Chonnam National University
}

\begin{abstract}
This paper introduces the simple and standard Cournot duopoly model in a symmetric situation in which each firm has the same information on the cost function of its rival. This paper considers two types of firms' risk-taking behaviours and two classes of symmetric information. First, we consider that both firms are risk neutral and have perfect information. In this case, we obtain a unique Cournot equilibrium. Second, when both firms are risk neutral and have partial information, that is, each firm's set of information changes from perfect to partial information, the number of equilibrium changes from one to four compared to case 1 . Third, when both firms are risk averse and have perfect information, that is, firms' risk taking behaviours change from risk neutral to risk averse, the number of equilibrium changes from one to three compared to case 1 . Therefore, both firms' information structure and risk taking behaviours affect their optimal output strategies.
\end{abstract}

Keywords: Cournot equilibrium, risk aversion, risk neutrality, symmetric information JEL classification: D81, F23, L13

\section{Introduction}

Firms producing some specific goods such as smart-phones and hybrid cars equipped with high technology compete with each other in the domestic or international market. Their risk taking behaviours in the face of market uncertainty are different and affect their rivals' behaviours and market shares. Most of these products are produced in industries with few firms.

Previous studies, including those by Appelbaum and Katz (1986), Appelbaum and Lim (1982), Fama and Laffer (1972), Fishelson (1989), Ishii (1989), Klemperer and Meyer (1986), Leland (1972), and Sandmo (1971) examined the effects of uncertainty on firms' behaviours assuming perfect information in the market or uncertainty in perfectly competitive commodity and factor markets. However, they do not explicitly consider conjectures of firms about the rival firm. In this paper, we assume that each firm does not know the other firm's cost structure at the time the output is produced and so

\footnotetext{
* This work was supported by a Research Grant of Andong National University.

a Department of Economics, Andong National University, Andong 760-749, Republic of Korea. Email: syryu@ andong.ac.kr (first author)

b Department of Economics, Chonnam National University, Gwangju 500-757, Republic of Korea. Email: kit2603@jnu.ac.kr (Corresponding author)
} 
conjectures the other firm's cost structure with its own information. For analytical convenience, we adopt the Cournot duopoly model in which only two firms exist.

There is a growing number of studies discussing duopoly models with information that assumes each firm is risk neutral and can share or exchange its private information on market uncertainty with its rival. This line of research focuses on a key factor of market uncertainty such as uncertain market demand or firms' unknown constant marginal costs. With respect to uncertain market demand, Novshek and Sonnenschein (1982) examined firms' incentives to share their private information about unknown market demand, and concluded that firms would not benefit from sharing their information. Clarke (1983a; 1983b) and Vives (1984) examined Novshek and Sonnenschein's result in a Cournot duopoly model and confirmed it. Gal-Or (1985) found that sharing their information on unknown market demand rather by keeping it private can provide firms with higher profit. Gehrig and Stenbacka (2007) investigated information sharing with repeated banking competition and found that information sharing reduces the benefits and therefore relaxes competition for initial market share. Richter (2013) analysed the Cournot oligopoly model in which firms face incomplete information related to production capacities, and showed that sharing information increased expected output and social welfare.

However, Li (1985) showed that firms producing homogenous products would not be profitable when they exchange information about uncertain demand. Uncertainty made firms more profitable. On the other hand, in cases of firms with uncertain marginal cost, Gal-Or (1986) and Shapiro (1986) showed that firms producing substitute goods would benefit from sharing their private information on their costs. Other important works concerning information sharing on uncertain demand or unknown costs are Doyle and Snyder (1999), Hwang (1993), Jin (1996), Kirby (1988), Malueg and Tsutsui (1996; 1998), Sakai (1990; 1991), and Sakai and Yamato (1989). The literature cited here analysed risk-neutral duopoly firms that share or exchange information and is based on a finite repeated game. In this paper, we extend the finite repeated game to an infinite repeated game and incorporate firms' risk-taking behaviours into a Cournot duopoly model.

This paper considers a simple Cournot duopoly model with unknown marginal costs in an infinite repeated game and assumes that there is no information sharing or exchange between firms. The main purpose of this paper is twofold. First, we investigate how firms with the same risk-taking behaviours react to the rival's strategy to address change in the information on the cost function. Second, we examine how firms with the same information structure react to the rival's strategy to address change in risk taking behaviours.

First, this paper considers the simple and standard Cournot duopoly model in which each firm has the same information set about the rival's cost function, but there is no information sharing or exchange between firms. In a traditional Cournot duopoly model, each firm's optimal output depends on both its own cost function and the other firm's cost function. Thus, when the information on the cost function is given, each firm has to use its beliefs about the other firm's cost function, and then we can summarise these beliefs in a subjective probability distribution. 
Second, we introduce two types of risk-taking behaviours and two classes of symmetric information. First, when both firms are risk neutral and the set of information of each firm changes from perfect to partial, we compare these firms' optimal strategies for the change in information set. Second, when both firms have perfect information and their risk taking behaviours change from risk neutral to risk averse, we compare these firms' optimal strategies for the change in their risk taking behaviours. Sandmo (1971) found that the expected utility maximising firm with risk aversion shows some different behaviour from the expected profit maximising firm with risk neutrality. We use Sandmo's approach to analyse the change in the firms' risk taking behaviours.

The remainder of this paper is organised as follows. Section 2 introduces the basic and standard duopoly model and analyses three cases: (i) both firms are risk neutral and have perfect information, (ii) both firms are risk neutral and have partial information, and (iii) both firms are risk averse and have perfect information. Finally, section 3 provides concluding remarks.

\section{The Model and Analysis}

We introduce a simple Cournot duopoly model in which two firms produce identical products and compete with each other in a market. The inverse linear market demand function is given by:

$$
P=a-q_{i}-q_{j}
$$

where $q_{i}$ denotes the amount of output produced by firm $i$, the demand intercept is $a$ and the slope of market demand is 1 for simplicity. We assume that firms have no fixed costs and the marginal cost of firm $i$ is constant and equal to $c_{i}\left(c_{i}>0\right)$. When firms have perfect knowledge of the other's cost function, the profit function of firm $i$ is

$$
\pi_{i}=\left(a-q_{i}-q_{j}-c_{i}\right) q_{i}, \text { for } i, j=1,2 \quad i \neq j
$$

From the profit maximisation problem of (1), the standard Cournot equilibrium for firm $i$ under perfect information, $q_{i}^{c}$ is

$$
q_{i}^{c}=\frac{1}{3}\left(a-2 c_{i}+c_{j}\right), \quad \text { for } i, j=1,2 \quad i \neq j
$$

We consider that each firm knows exactly its own constant marginal cost but the set of information about the rival's marginal cost available to each firm is different. That is, each firm has its subjective probability distribution about the rival's constant marginal cost. Before proceeding, we define the random variables to distinguish them from the non-random variables given the set of information available to each firm as follows:

$$
q_{j}\left|\Omega_{i}, c_{j}\right| \Omega_{i} \text {, and } \pi_{i} \mid \Omega_{i}, \text { for } i, j=1,2 \quad i \neq j
$$

where $\Omega_{i}$ is the set of information available to firm $i$. 


\subsection{Case 1: Both Firms are Risk Neutral and have Perfect Information}

We assume that both firms are risk neutral and have perfect information. Each firm chooses its output to maximise its expected profit conditional on its private information. Firm i's expected profit function given its private information, $\Omega_{i}$ is

$$
\begin{aligned}
E\left(\pi_{i} \mid \Omega_{i}\right) & =E\left\{\left(a-q_{i}-q_{j}-c_{i} \mid \Omega_{i}\right) q_{i}\right\} \\
& =\left\{a-q_{i}-c_{i}-E\left(q_{j} \mid \Omega_{i}\right)\right\} q_{i}, \quad \text { for } i, j=1,2 \quad i \neq j
\end{aligned}
$$

where $E$ is the expectations operator.

We assume that each firm has its subjective probability distribution about the rival's constant marginal cost as in the following.

Assumption: Let firm j's expectation about $c_{i}$ be $E\left(c_{i} \mid \Omega_{j}\right)=c_{i}+b_{i}$; where $b_{i}$ is a small (relative to $c_{i}$ ) non-systematic bias. This implies that firm i's expectation about firm $j$ 's expectation bias, $b_{i}$ is zero: $E\left(b_{i} \mid \Omega_{i}\right)=0$. Then,

$$
\begin{aligned}
& E\left[E\left(c_{i} \mid \Omega_{j}\right) \mid \Omega_{i}\right]=E\left[\left(c_{i}+b_{i}\right) \mid \Omega_{i}\right]=c_{i}+E\left(b_{i} \mid \Omega_{i}\right)=c_{i} \\
& E\left\{\cdots E\left[E\left(c_{i} \mid \Omega_{j}\right) \mid \Omega_{i}\right] \cdots \mid \Omega_{i}\right\}=E\left[E\left(c_{i} \mid \Omega_{j}\right) \mid \Omega_{i}\right]=c_{i} \\
& E\left\{\cdots E\left[E\left(c_{i} \mid \Omega_{j}\right) \mid \Omega_{i}\right] \cdots \mid \Omega_{j}\right\}=E\left(c_{i} \mid \Omega_{j}\right)=c_{i}+b_{i}
\end{aligned}
$$

We now consider the symmetric situation in which both firms have perfect information about the constant marginal cost of the rival firm. That is,

$$
E\left(c_{1} \mid \Omega_{2}\right)=c_{1} \text { and } E\left(c_{2} \mid \Omega_{1}\right)=c_{2}
$$

From the first-order condition of (3), we can write the best reaction function for each as:

$$
\begin{aligned}
& q_{1}=\frac{1}{2}\left\{a-c_{1}-E\left(q_{2} \mid \Omega_{1}\right)\right\} \\
& q_{2}=\frac{1}{2}\left\{a-c_{2}-E\left(q_{1} \mid \Omega_{2}\right)\right\}
\end{aligned}
$$

This unique Cournot equilibrium can vary, depending on each firm's expectation based on the other firm's information set, $E\left(q_{j} \mid \Omega_{i}\right)$. Thus, the expected reaction function of one firm based on the given information set of the other firm is as follows.

The expected reaction function of firm 1 based on the information set of firm 2 in round 0 is

$$
E\left(q_{1} \mid \Omega_{2}\right)=E\left\{\frac{1}{2}\left[a-c_{1}-E\left(q_{2} \mid \Omega_{1}\right)\right] \mid \Omega_{2}\right\}
$$


The expected reaction function of firm 2 based on the information set of firm 1 in round 0 is

$$
E\left(q_{2} \mid \Omega_{1}\right)=E\left\{\frac{1}{2}\left[a-c_{2}-E\left(q_{1} \mid \Omega_{2}\right)\right] \mid \Omega_{1}\right\}
$$

Substituting (6) into (7), we get

$$
\begin{aligned}
E\left(q_{2} \mid \Omega_{1}\right) & =E\left\{\frac{1}{2}\left[a-c_{2}-E\left\{\frac{1}{2}\left[a-c_{1}-E\left(q_{2} \mid \Omega_{1}\right) \mid \Omega_{2}\right]\right\} \mid \Omega_{1}\right]\right\} \\
& =\left(\frac{1}{2}-\frac{1}{4}\right) a-\frac{1}{2} E\left(c_{2} \mid \Omega_{1}\right)+\frac{1}{4} E\left[\left(c_{1} \mid \Omega_{2}\right) \mid \Omega_{1}\right]+\frac{1}{4} E\left\{\left[\left(q_{2} \mid \Omega_{1}\right) \mid \Omega_{2}\right] \mid \Omega_{1}\right\}
\end{aligned}
$$

Using $E\left(c_{2} \mid \Omega_{1}\right)=c_{2}, E\left[\left(c_{1} \mid \Omega_{2}\right) \mid \Omega_{2}\right]=c_{1}$ and $E\left\{\left[\left(q_{2} \mid \Omega_{1}\right) \mid \Omega_{2}\right] \mid \Omega_{1}\right\}=E\left(q_{2} \mid \Omega_{1}\right)$, we have

$$
E\left(q_{2} \mid \Omega_{1}\right)=\left(\frac{1}{2}-\frac{1}{4}\right) a-\frac{1}{2} c_{2}+\frac{1}{4} c_{1}+\frac{1}{4} E\left(q_{2} \mid \Omega_{1}\right)
$$

Substituting (7) into (9), we get the expected reaction function of firm 2:

$$
E\left(q_{2} \mid \Omega_{1}\right)=\left(\frac{1}{2}-\frac{1}{4}\right) a-\frac{1}{2} c_{2}+\frac{1}{4} c_{1}+\frac{1}{4}\left[E\left\{\frac{1}{2}\left[a-c_{2}-E\left(q_{1} \mid \Omega_{2}\right)\right] \mid \Omega_{1}\right\}\right]
$$

That is,

$$
E\left(q_{2} \mid \Omega_{1}\right)=\left(\frac{1}{2}-\frac{1}{4}+\frac{1}{8}\right) a-\left(\frac{1}{2}+\frac{1}{8}\right) c_{2}+\frac{1}{4} c_{1}-\frac{1}{8} E\left[\left(q_{1} \mid \Omega_{2}\right) \mid \Omega_{1}\right]
$$

We call this equation the expected reaction function of firm 2 based on the information set of firm 1 in round 1.

In round 2,

$$
\begin{aligned}
E\left(q_{2} \mid \Omega_{1}\right)= & \left(\frac{1}{2}-\frac{1}{4}+\frac{1}{8}-\frac{1}{16}+\frac{1}{32}\right) a-\left(\frac{1}{2}+\frac{1}{8}+\frac{1}{32}\right) c_{2} \\
& +\left(\frac{1}{4}+\frac{1}{16}\right) c_{1}-\frac{1}{32} E\left[\left(q_{1} \mid \Omega_{2}\right) \mid \Omega_{1}\right]
\end{aligned}
$$

Hence, we have a sequence of expected reaction functions of firm 2 based on the information set of firm 1.

In round $n$, we get

$$
\begin{aligned}
E\left(q_{2} \mid \Omega_{1}\right)= & \left(\frac{1}{2}-\frac{1}{4}+\frac{1}{8}-\frac{1}{16}+\frac{1}{32}+\cdots+\frac{1}{2}\left(\frac{1}{2}\right)^{2 n+1}\right) a-\left(\frac{1}{2}+\frac{1}{8}+\frac{1}{32}+\cdots+\frac{1}{2}\left(\frac{1}{4}\right)^{n}\right) c_{2} \\
& +\left(\frac{1}{4}+\frac{1}{16}+\cdots+\frac{1}{4}\left(\frac{1}{4}\right)^{n-1}\right) c_{1}-\frac{1}{8}\left(\frac{1}{4}\right)^{n-1} E\left[\left(q_{1} \mid \Omega_{2}\right) \mid \Omega_{1}\right]
\end{aligned}
$$


Thus, in the limit, we have

$$
E\left(q_{2} \mid \Omega_{1}\right)=\frac{1}{3} a-\frac{2}{3} c_{2}+\frac{1}{3} c_{1}
$$

Similarly, we have the expected reaction function of firm 1 based on the information set of firm 2,

$$
E\left(q_{1} \mid \Omega_{2}\right)=\frac{1}{3} a-\frac{2}{3} c_{1}+\frac{1}{3} c_{2}
$$

Inserting (13) and (14) into (4) and (5), respectively, we finally obtain the unique Cournot equilibrium $\left(q_{1}^{c}, q_{2}^{c}\right)$ :

$$
\begin{aligned}
& q_{1}^{c}=\frac{1}{3}\left(a-2 c_{1}+c_{2}\right) \\
& q_{2}^{c}=\frac{1}{3}\left(a-2 c_{2}+c_{1}\right)
\end{aligned}
$$

Figure 1 illustrates these best reaction curves for firms 1 and 2 by round.

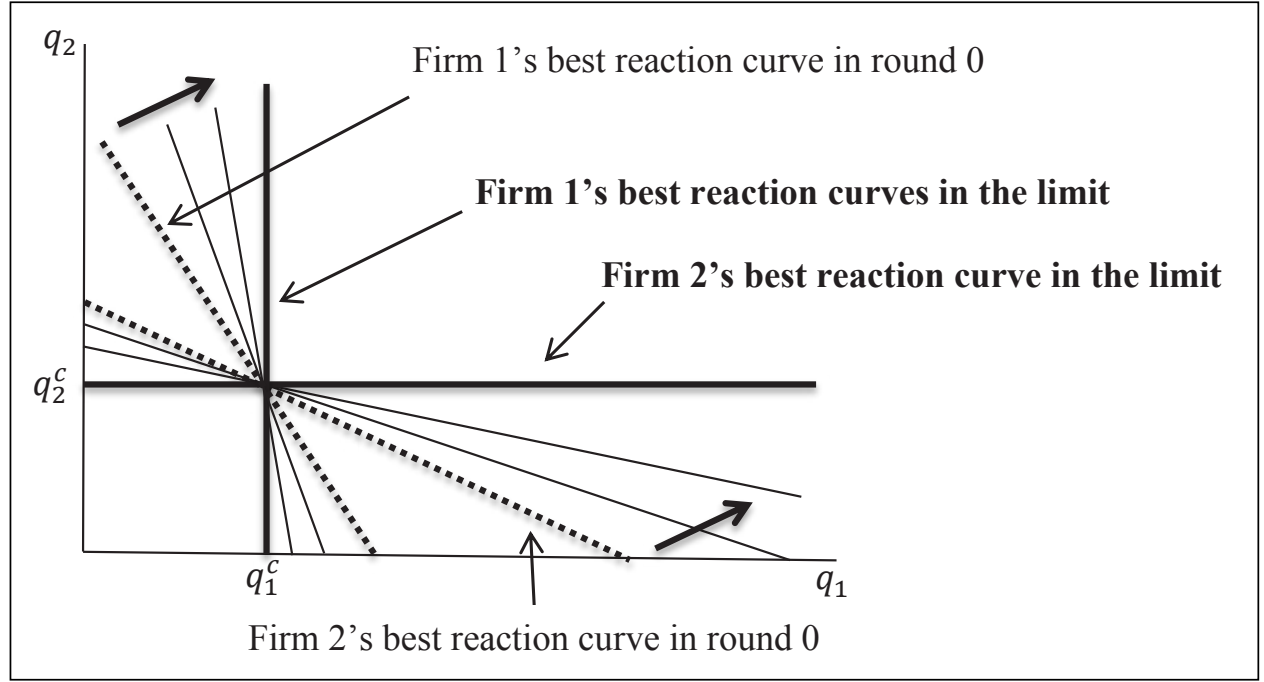

Figure 1. Cournot equilibrium under perfect information

\subsection{Case 2: Both Firms are Risk Neutral and have Partial Information}

Next, we investigate the case in which both firms are risk neutral and have partial information about the constant marginal cost of the rival firm. That is,

$$
E\left(c_{1} \mid \Omega_{2}\right)=c_{1}+b_{1} \text { and } E\left(c_{2} \mid \Omega_{1}\right)=c_{2}+b_{2}
$$


Using $E\left(c_{2} \mid \Omega_{1}\right)=c_{2}+b_{2}, E\left[\left(c_{1} \mid \Omega_{2}\right) \mid \Omega_{2}\right]=c_{1}$ and $E\left\{\left[\left(q_{2} \mid \Omega_{1}\right) \mid \Omega_{2}\right] \mid \Omega_{1}\right\}=E\left(q_{2} \mid \Omega_{1}\right)$, from (8) we have

$$
E\left(q_{2} \mid \Omega_{1}\right)=\left(\frac{1}{2}-\frac{1}{4}\right) a-\frac{1}{2}\left(c_{2}+b_{2}\right)+\frac{1}{4} c_{1}+\frac{1}{4} E\left(q_{2} \mid \Omega_{1}\right)
$$

As the round goes on, at the limit, we get

$$
E\left(q_{2} \mid \Omega_{1}\right)=\frac{1}{3} a-\frac{2}{3}\left(c_{2}+b_{2}\right)+\frac{1}{3} c_{1}
$$

Similarly, we have the expected reaction function of firm 1 based on firm 2's information set, $E\left(q_{1} \mid \Omega_{2}\right)$.

$$
E\left(q_{1} \mid \Omega_{2}\right)=\frac{1}{3} a-\frac{2}{3}\left(c_{1}+b_{1}\right)+\frac{1}{3} c_{2}
$$

Inserting (18) and (19) into (4) and (5), respectively, we finally obtain the Cournot equilibrium $\left(q_{1}^{*}, q_{2}^{*}\right)$ with partial information as:

$$
\begin{aligned}
& q_{1}^{*}=\frac{1}{3}\left\{a-2 c_{1}+\left(c_{2}+b_{2}\right)\right\} \\
& q_{2}^{*}=\frac{1}{3}\left\{a-2 c_{2}+\left(c_{1}+b_{1}\right)\right\}
\end{aligned}
$$

Let the upper and lower bound of the bias, $b_{2}\left(b_{1}\right)$ be denoted by $b_{2}^{u}\left(b_{1}^{u}\right)$ and $b_{2}^{\ell}\left(b_{1}^{\ell}\right)$ respectively; then, we can write the expected reaction function of firm 2 (or firm 1 ) based on the information set of firm 1 (or firm 2) as:

$$
\begin{aligned}
& q_{1}^{\ell^{*}}=\frac{1}{3}\left\{a-2 c_{1}+\left(c_{2}+b_{2}^{\ell}\right)\right\} \text { and } q_{1}^{u^{*}}=\frac{1}{3}\left\{a-2 c_{1}+\left(c_{2}+b_{2}^{u}\right)\right\} \\
& q_{2}^{e^{*}}=\frac{1}{3}\left\{a-2 c_{2}+\left(c_{1}+b_{1}^{\ell}\right)\right\} \text { and } q_{2}^{u^{*}}=\frac{1}{3}\left\{a-2 c_{2}+\left(c_{1}+b_{1}^{u}\right)\right\}
\end{aligned}
$$

Now, compared to case 1 with perfect information, we have four Cournot equilibria: $\left(q_{1}^{\ell^{*}}, q_{2}^{\ell^{*}}\right),\left(q_{1}^{\ell^{*}}, q_{2}^{u^{*}}\right),\left(q_{1}^{u^{*}}, q_{2}^{\ell^{*}}\right)$ and $\left(q_{1}^{u^{*}}, q_{2}^{u^{*}}\right)$. That is, if the firm's set of information changes from perfect to partial information, the number of equilibria changes. Figure 2 illustrates this case.

\subsection{Case 3: Both Firms are Risk Averse and have Perfect Information}

We now assume that both firms are risk averse $u^{\prime}(\pi)>0$ and $u^{\prime \prime}(\pi)<0$ and each firm has perfect information about the constant marginal cost of the rival firm.

The objective function of the expected utility maximising firm 1 is

$$
E\left[u_{1}\left(\pi_{1} \mid \Omega_{1}\right)\right]=E\left\{u_{1}\left[\left(a-q_{1}-q_{2}-c_{1} \mid \Omega_{1}\right) q_{1}\right]\right\}
$$




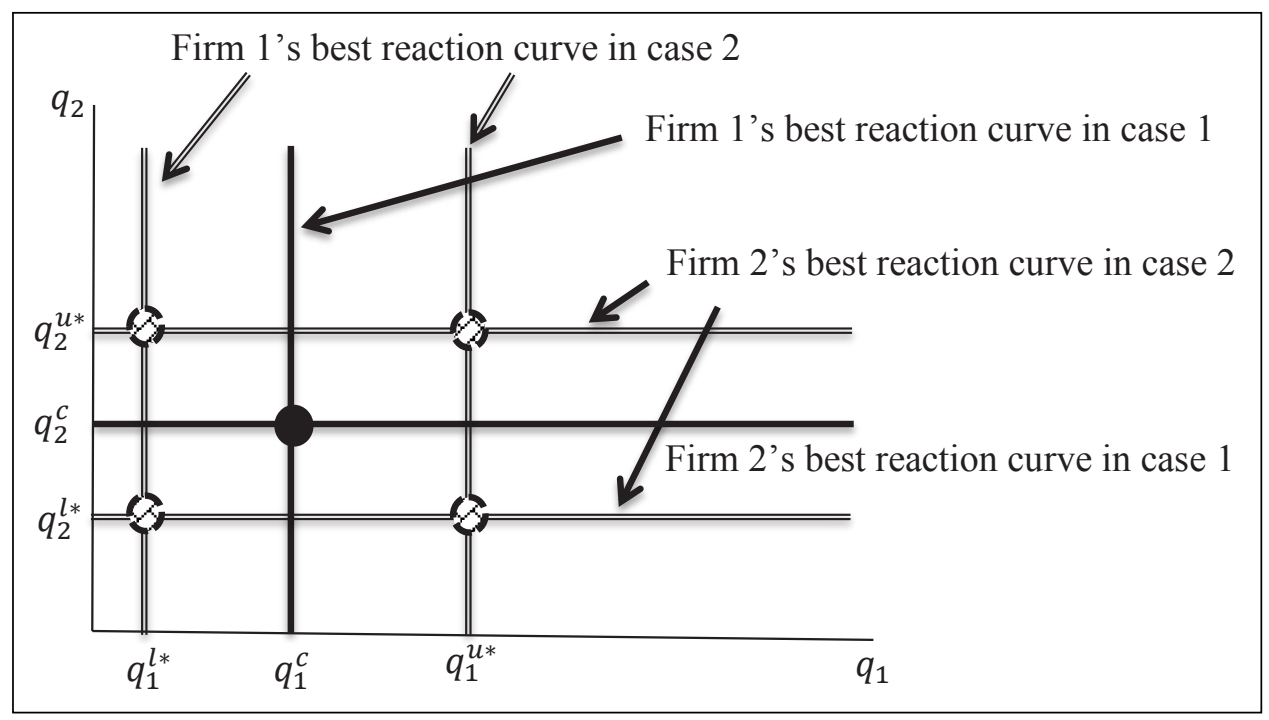

Figure 2. Cournot duopoly equilibria in case 2 compared to case 1

We can write the first- and second-condition as:

$$
E\left[u_{1}^{\prime}\left(\pi_{1} \mid \Omega_{1}\right)\left(a-2 q_{1}-c_{1}-\left(q_{2} \mid \Omega_{1}\right)\right)\right]=0
$$

and

$$
E\left\{u_{1}^{\prime \prime}\left(\pi_{1} \mid \Omega_{1}\right)\left[a-2 q_{1}-c_{1}-\left(q_{2} \mid \Omega_{1}\right)\right]^{2}-2 u_{1}^{\prime}\left(\pi_{1} \mid \Omega_{1}\right)\right\}<0
$$

The second-order condition is always satisfied because, for the risk averse firm, $u_{1}^{\prime}(\cdot)>0$ and $u_{1}^{\prime \prime}(\cdot)<0$.

From the first-order condition (25), $E\left[u_{1}^{\prime}\left(\pi_{1} \mid \Omega_{1}\right)\left(a-2 q_{1}-c_{1}\right)\right]=E\left[u_{1}^{\prime}\left(\pi_{1} \mid \Omega_{1}\right)\left(q_{2} \mid \Omega_{1}\right)\right]$.

Subtracting $E\left[u_{1}^{\prime}\left(\pi_{1} \mid \Omega_{1}\right) E\left(q_{2} \mid \Omega_{1}\right)\right]$ from both sides; then,

$$
E\left\{u_{1}^{\prime}\left(\pi_{1} \mid \Omega_{1}\right)\left[a-2 q_{1}-c_{1}-E\left(q_{2} \mid \Omega_{1}\right)\right]\right\}=E\left\{u_{1}^{\prime}\left(\pi_{1} \mid \Omega_{1}\right)\left[q_{2} \mid \Omega_{1}-E\left(q_{2} \mid \Omega_{1}\right)\right]\right\}
$$

From the symmetric uncertainty of expected utility maximisation in Sandmo (1971, p. 67), we propose:

$$
\pi_{1} \mid \Omega_{1}=\left(a-q_{1}-c_{1}-q_{2} \mid \Omega_{1}\right) q_{1} \text { and } E\left(\pi_{1} \mid \Omega_{1}\right)=\left[a-q_{1}-c_{1}-E\left(q_{2} \mid \Omega_{1}\right)\right] q_{1}
$$

Thus, $\pi_{1} \mid \Omega_{1}-E\left(\pi_{1} \mid \Omega_{1}\right)=-\left[q_{2} \mid \Omega_{1}-E\left(q_{2} \mid \Omega_{1}\right)\right] q_{1}$

Clearly, it follows that:

$$
u_{1}^{\prime}\left(\pi_{1} \mid \Omega_{1}\right) \geq u_{1}^{\prime}\left[E\left(\pi_{1} \mid \Omega_{1}\right)\right], \text { if } q_{2} \mid \Omega_{1} \geq E\left(q_{2} \mid \Omega_{1}\right)
$$


Now the following inequality holds for all $q_{2} \mid \Omega_{1}$ :

$$
u_{1}^{\prime}\left(\pi_{1} \mid \Omega_{1}\right)\left[q_{2} \mid \Omega_{1}-E\left(q_{2} \mid \Omega_{1}\right)\right] \geq u_{1}^{\prime}\left[E\left(\pi_{1} \mid \Omega_{1}\right)\right]\left[q_{2} \mid \Omega_{1}-E\left(q_{2} \mid \Omega_{1}\right)\right]
$$

Taking the expectations on both sides:

$$
\begin{gathered}
E\left\{u_{1}^{\prime}\left(\pi_{1} \mid \Omega_{1}\right)\left[q_{2} \mid \Omega_{1}-E\left(q_{2} \mid \Omega_{1}\right)\right]\right\} \geq E\left\{u_{1}^{\prime}\left[E\left(\pi_{1} \mid \Omega_{1}\right)\right]\left[q_{2} \mid \Omega_{1}-E\left(q_{2} \mid \Omega_{1}\right)\right]\right\} \\
=u_{1}^{\prime}\left[E\left(\pi_{1} \mid \Omega_{1}\right)\right]\left[E\left(q_{2} \mid \Omega_{1}\right)-E\left(q_{2} \mid \Omega_{1}\right)\right]=0
\end{gathered}
$$

From (27) and (30),

$$
\begin{aligned}
E\left\{u_{1}^{\prime}\left(\pi_{1} \mid \Omega_{1}\right)\left[a-2 q_{1}-c_{1}-E\left(q_{2} \mid \Omega_{1}\right)\right]\right\} & \\
= & {\left[a-2 q_{1}-c_{1}-E\left(q_{2} \mid \Omega_{1}\right)\right] E\left[u_{1}^{\prime}\left(\pi_{1} \mid \Omega_{1}\right)\right] \geq 0 }
\end{aligned}
$$

This implies that, for an optimal decision, the following inequality must be satisfied:

$$
q_{1} \leq \frac{1}{2}\left[a-c_{1}-E\left(q_{2} \mid \Omega_{1}\right)\right]
$$

which is the best reaction function of firm 1 . Similarly, we obtain the best reaction of firm 2:

$$
q_{2} \leq \frac{1}{2}\left[a-c_{2}-E\left(q_{1} \mid \Omega_{2}\right)\right]
$$

In the present model, each firm does in fact react to the expected reaction function of the other firm based on its own information set. Let $r_{i j}$ be firm i's response to the change in firm $j$ 's expected output level based on its own information set. $r_{i j}$ is equal to or less than -(1/2) under perfect information in (32) and (33). This means that if firm $i$, based on its own information set, anticipates a reduction in firm $j$ 's output by 1 unit, then firm 1 increases its output by less than or equal to $1 / 2$ unit. That is, this makes firm $i$ 's reaction curve move inward by $k_{i}(>0)$ under perfect information. Let $k_{i}$ be firm $i$ 's output reduction under perfect information; the best reaction functions of both firms in (32) and (33) can be written as:

$$
\begin{aligned}
& q_{1}=\frac{1}{2}\left[a-c_{1}-E\left(q_{2} \mid \Omega_{1}\right)\right]-k_{1} \\
& q_{2}=\frac{1}{2}\left[a-c_{2}-E\left(q_{1} \mid \Omega_{2}\right)\right]-k_{2}
\end{aligned}
$$

From (34), the expected reaction function of firm 1 based on the information set of firm 2 in round 0 is

$$
E\left(q_{1} \mid \Omega_{2}\right)=E\left\{\frac{1}{2}\left[a-c_{1}-E\left(q_{2} \mid \Omega_{1}\right) \mid \Omega_{2}\right]-k_{1}\right\}
$$

From (35), the expected reaction function of firm 2 based on the information set of firm 1 in round 0 is

$$
E\left(q_{2} \mid \Omega_{1}\right)=E\left\{\frac{1}{2}\left[a-c_{2}-E\left(q_{1} \mid \Omega_{2}\right) \mid \Omega_{1}\right]-k_{2}\right\}
$$


By calculating the value as in case 1 , we get the best reaction of each firm, respectively

$$
\begin{aligned}
& \tilde{q}_{1}^{*}=\frac{1}{3} a-\frac{2}{3} c_{1}+\frac{1}{3} c_{2}+\frac{2}{3} k_{2}-\frac{4}{3} k_{1}=q_{1}^{c}+\frac{2}{3} k_{2}-\frac{4}{3} k_{1} \\
& \tilde{q}_{2}^{*}=\frac{1}{3} a-\frac{2}{3} c_{2}+\frac{1}{3} c_{1}+\frac{2}{3} k_{1}-\frac{4}{3} k_{2}=q_{2}^{c}+\frac{2}{3} k_{1}-\frac{4}{3} k_{2}
\end{aligned}
$$

where $q_{1}^{c}$ and $q_{2}^{c}$ are the Cournot equilibrium in case 1 .

Let $k_{i} / k_{i}$ be the relative size of the amount of output from both firms which is reduced under risk aversion. The values of $k$ measure the difference in firms' reaction in terms of risk taking behaviours.

Compared to case 1 , where both firms are risk neutral and have perfect information, we get three possible Cournot equilibria for the different values of the ratio of $k$. Because they have the same information set but show different risk taking behaviours, they have different strategies from those in case 1. Figure 3 illustrates this case.

(i) If $0 \leq \frac{k_{2}}{k_{1}} \leq \frac{1}{2}$, then $\tilde{q}_{1}^{*}<q_{1}^{c}$ and $\tilde{q}_{2}^{*}>q_{2}^{c}$ ( $a$ in Figure 3 ).

(ii) If $\frac{1}{2} \leq \frac{k_{2}}{k_{1}} \leq 2$, then $\tilde{q}_{1}^{*} \leq q_{1}^{c}$ and $\tilde{q}_{2}^{*} \leq q_{2}^{c}(b$ in Figure 3$)$.

(iii) If $\frac{k_{2}}{k_{1}}>2$, then $\tilde{q}_{1}^{*}>q_{1}^{c}$ and $\tilde{q}_{2}^{*}<q_{2}^{c}$ (c in Figure 3 ).

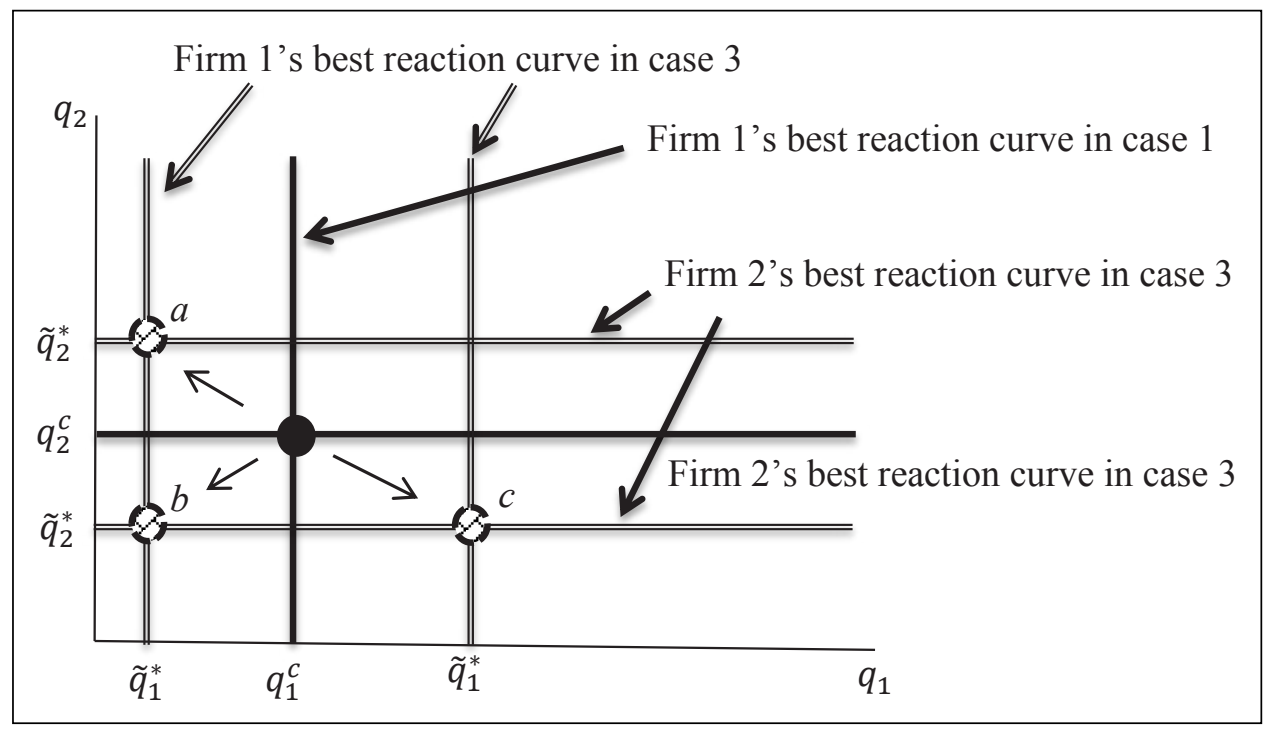

Figure 3. Cournot duopoly equilibria in case 3 compared to case 1 


\section{Concluding Remarks}

This paper discusses the Cournot duopolists facing a symmetric situation in which both firms in a market have the same information structure and risk taking behaviours. First, we consider that both firms are risk neutral and have perfect information. In this case, the equilibrium strategies are the same as in the standard Cournot cases. Second, when both firms are risk neutral and have partial information, that is, each firm's set of information changes from perfect to partial information, the number of equilibrium changes from one to four compared to case 1 . Third, when both firms are risk averse and have perfect information, that is, the firms' risk taking behaviours change from risk neutral to risk averse, the number of equilibrium changes from one to three compared to case 1 . Therefore, both firms' information structure and risk taking behaviours affect their optimal output strategies and market shares.

\section{References}

Appelbaum, E., \& Katz, E. (1986). Measures of risk aversion and comparative statics of industry equilibrium. The American Economic Review, 76(3), 524-529.

Appelbaum, E., \& Lim, C. (1982). Long run industry equilibrium with uncertainty. Economics Letters, 9(2), 139-145. https://doi.org/10.1016/0165-1765(82)90005-2

Clarke, R.N. (1983a). Collusion and the incentives for information sharing. The Bell Journal of Economics, 14(2), 383-394. doi: 10.2307/3003640

Clarke, R.N. (1983b). Duopolist don't wish to share information. Economics Letters, 14(1-2), 33-36. https://doi.org/10.1016/0165-1765(83)90158-1

Doyle, M.P., \& Snyder, C.M. (1999). Information sharing and competition in the motor vehicle industry. Journal of Political Economy, 107(6), 1326-1364. doi: 10.1086/250099

Fama, E.F., \& Laffer, A.B. (1972). The number of firms and competition. The American Economic Review, 62(4), 670-674.

Fishelson, G. (1989). Imperfect competition under uncertainty. Journal of Economics and Business, 41(3), 253-263. doi: 10.1016/0148-6195(89)90023-4

Gehrig, T., \& Stenbacka, R. (2007). Information sharing and lending market competition with switching costs. European Economic Review, 51(1), 77-99. https://doi.org/10.1016/j. euroecorev.2006.01.009

Gal-Or, R. (1985). Information sharing in oligopoly. Econometrica, 53(2), 329-343. doi: 10.2307/ 1911239

Gal-Or, R. (1986). Information transmission-Cournot and Bertrand equilibria. The Review of Economic Studies, 53(1), 85-92. https://doi.org/10.2307/2297593

Hwang, H.S. (1993). Optimal information acquisition for heterogeneous duopoly firms. Journal of Economic Theory, 59(2), 385-402. https://doi.org/10.1006/jeth.1993.1024

Ishii, Y. (1989). Measures of risk aversion and comparative statics of industry equilibrium: Correction. The American Economic Review, 79(1), 285-286.

Jin, J.Y. (1996). A test for information sharing in Cournot oligopoly. Information Economics and Policy, 8(1), 75-86. https://doi.org/10.1016/0167-6245(95)00014-3

Kirby, A. (1988). Trade associations as information exchange mechanism. The RAND Journal of Economics, 19(1), 138-146.

Klemperer, P., \& Meyer, M. (1986). Price competition vs. quantity competition: The role of uncertainty. The Rand Journal of Economics, 17(4), 618-638.

Leland, H.E. (1972). Theory of the firm facing uncertain demand. The American Economic Review, 62(3), 278-291. 
Li, L. (1985). Cournot oligopoly with information sharing. The Rand Journal of Economics, 16(4), 521-536. doi: $10.2307 / 2555510$

Malueg, D.A., \& Tsutsui, S.O. (1996). Duopoly information exchange: The case of unknown slope. International Journal of Industrial Organization, 14(1), 119-136. https://doi.org/10.1016/ 0167-7187(94)00468-4

Malueg, D.A., \& Tsutsui, S.O. (1998). Distributional assumptions in the theory of oligopoly information exchange. International Journal of Industrial Organization, 16(6), 785-797. https://doi.org/10.1016/S0167-7187(97)00026-X

Novshek, W., \& Sonnenschein, H. (1982). Fulfilled expectations Cournot duopoly with information acquisition and release. The Bell Journal of Economics, 13(1), 214-218. doi: 10.2307/3003442

Richter, J. (2013). Incomplete information in Cournot oligopoly: The case of unknown production capacities (EWI Working Paper, No. 13/01). Cologne, Germany: Institute of Energy Economics at the University of Cologne.

Sakai, Y. (1990). Information sharing in oligopoly: Overview and evaluation. Part I. Alternative models with a common risk. Keio Economic Studies, 27(2), 17-41.

Sakai, Y. (1991). Information sharing in oligopoly: Overview and evaluation. Part II. Private risks and oligopoly models. Keio Economic Studies, 28(1), 51-71.

Sakai, Y., \& Yamato, T. (1989). Oligopoly, information and welfare. Journal of Economics, 49(1), 3-24.

Sandmo, A. (1971). On the theory of the competitive firm under price uncertainty. The American Economic Review, 61(1), 65-73.

Shapiro, C. (1986). Exchange of cost information in oligopoly. The Review of Economic Studies, 53(3), 433-446. https://doi.org/10.2307/2297638

Vives, X. (1984). Duopoly information equilibrium: Cournot and Bertrand. Journal of Economic Theory, 34(1), 71-94. https://doi.org/10.1016/0022-0531(84)90162-5 